\begin{tabular}{|c|c|}
\hline is & $\begin{array}{l}\text { International Journal of Trend in Scientific Research and Development (IJTSRD) } \\
\text { International Open Access Journal | www.ijtsrd.com }\end{array}$ \\
\hline & EISSN No: 2456 - 6470 | Volume - 3 | Issue - 1 | Nov - Dec 2018 \\
\hline
\end{tabular}

\title{
Database System in Automatic Billing for Supermarket
}

\author{
Aye Thandar Htwe ${ }^{1}$, Aye Wint Mon ${ }^{2}$ \\ ${ }^{1}$ Assistant Lecturer, ${ }^{2}$ Associate Professor \\ Department of Electronic Engineering, Pyay Technological University, Pyay, Myanmar
}

\begin{abstract}
Now-a-day shopping in city-mark and mall is increasing rapidly. While shopping, customers have to face some difficulties. First, they go at the billing counter for payments their total expenditure but there are many people standing in queue for billing purpose. This is unnecessary waste time for customer because cashier scans each item bought with barcode. Barcode technology is time consuming process. Second, customer can't predict their total expenditure so overall purchase total is greater than their budget. Thus, the system overcomes all of these drawbacks faced by customers in shopping malls. This system has been introduced to avoid waiting in billing queue. The system consists of a RFID reader, Arduino Uno, LCD display and wireless Zigbee transmitter in the customer site and software programming language is Arduino IDE. At the counter computer, Zigbee receiver is connected to billing PC using serial communication. Visual Basic 6.0 is used for Graphical User Interface (GUI) to get display customer bill and Microsoft Access database system is used to know about details of purchasing products on the counter computer.
\end{abstract}

KEY WORDS: RFID, Zigbee, Visual Basic 6.0 and Microsoft Access

\section{INTRODUCTION}

Purchasing and shopping at big malls is becoming daily activity among people. The huge rush at malls is on holidays and weekends. The rush is even more when there are special offers and discount. People purchase different items and put them in trolley. After purchase customer need to go to billing counter for payments. At the billing counter the cashier prepare the bill using barcode reader which is a time consuming process and results in long queue at billing counter. The aim is to develop a system that can be used in shopping malls to solve the rush at billing counter by using "Automatic Billing for Supermarket."

Visual Basic 6.0 is necessary software to show bill details at the counter computer and linking Visual Basic 6.0 with Microsoft Access database system is daily record of purchasing product for shop owner. The system creates the structure of a database in design view with table. Field name column contains the names for customer purchasing date, total expenditure, item's names and prices and quantity for ten items. When the table is created in the Access, data type column specifies the type of data that the field can contain. The shop owner can see this table whenever he wanted.

\section{LITERATURE SURVEY}

Currently available method in supermarket is the barcode method. The cashier scans the product through the barcode scanner and gives the customer the total bill. But this method becomes a slow process when a lot of products are to be scanned which eventually results in long queues, making the billing process slow. While doing survey this is found that most of the people prefer to leave the shopping mall instead of waiting in long queues to buy a few products. To try to solve the problems previously identified, recent years have seen the appearance of several technological solutions for hypermarket assistance. All such solutions share the same objectives: save consumer's time and money.

\section{PROPOSED SYSTEM METHODOLOGY}

\section{A. Operation}

All of the product in the mall will be equipped with RFID tags. The customers scan the items containing predefined tags in front of the reader themselves. When a person puts any item in the trolley, its code 
International Journal of Trend in Scientific Research and Development (IJTSRD) ISSN: 2456-6470

will be detected and the name and prices of these products will be stored in memory. As a person put the products, the costs will get added to the total bill. When a customer wants to remove any product from the trolley, put erase card and the removed product needs to be scanned again then it deducts cost of that specific item from total amount.. Thus the billing will be done in the customer site. Item name and its cost will be displayed on LCD. At the billing counter the total bill data will be transferred to PC by wireless transmitter and receiver modules.

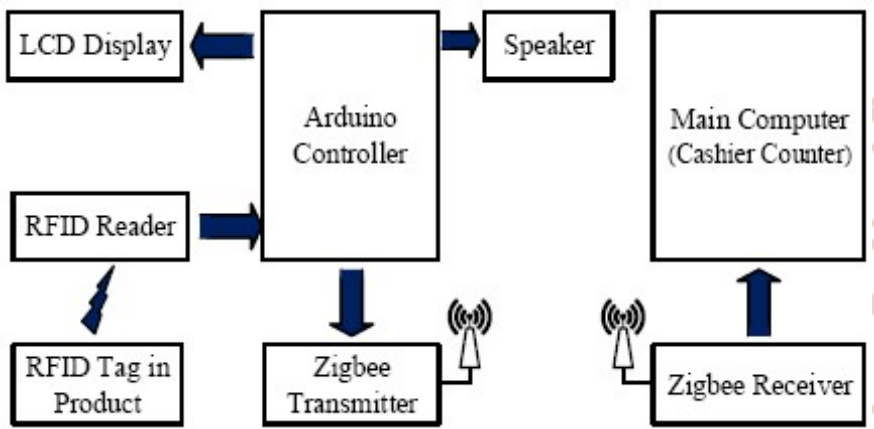

Fig1: Block Diagram of Automatic Billing for Supermarket

\section{B. System Flow Chat}

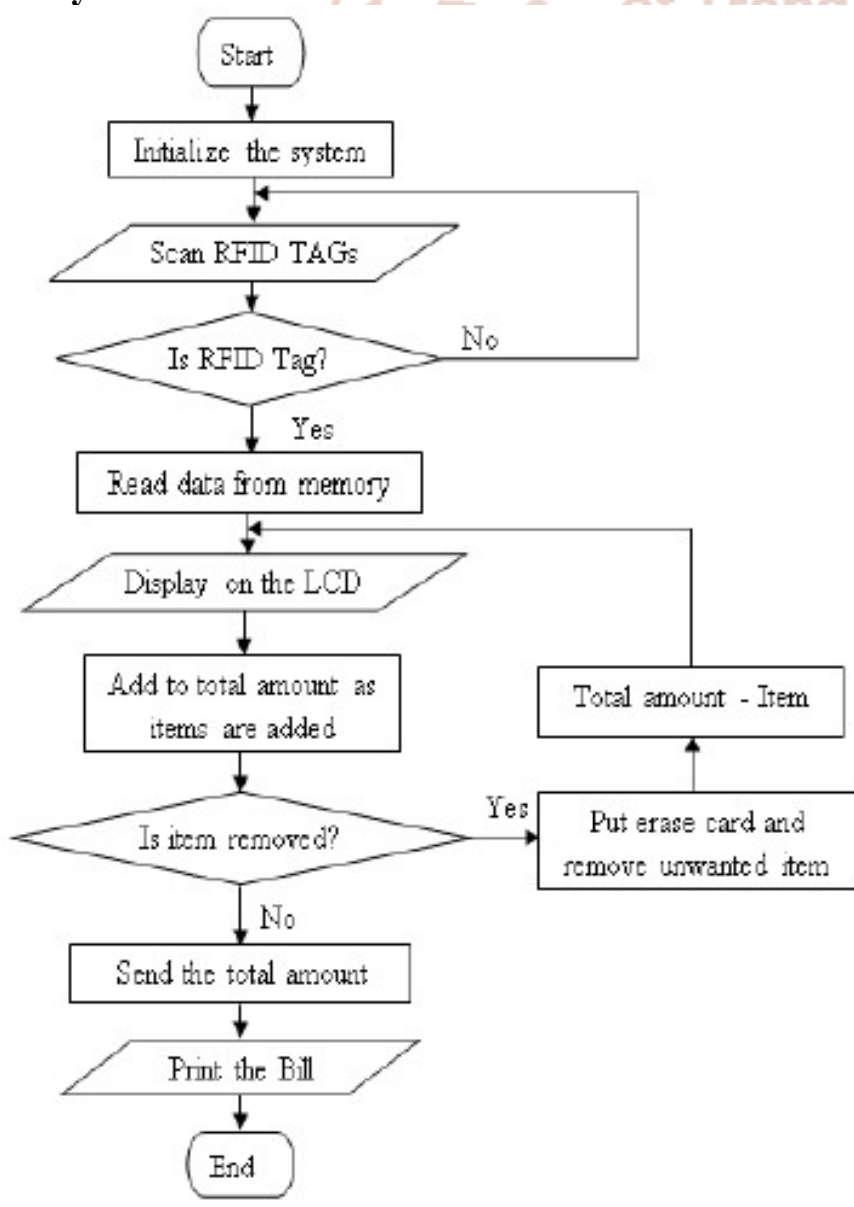

Fig 2: Data Flow Diagram

\section{DATABASE SYSTEM IN AUTOMATIC BILLING}

When opening Visual Basic start, take and open standard EXE from the new project window. At the form one into project one of the new project window draw table by using appropriate type of controls. If project window has the losses and missing of components, check standard toolbar from the view menu.

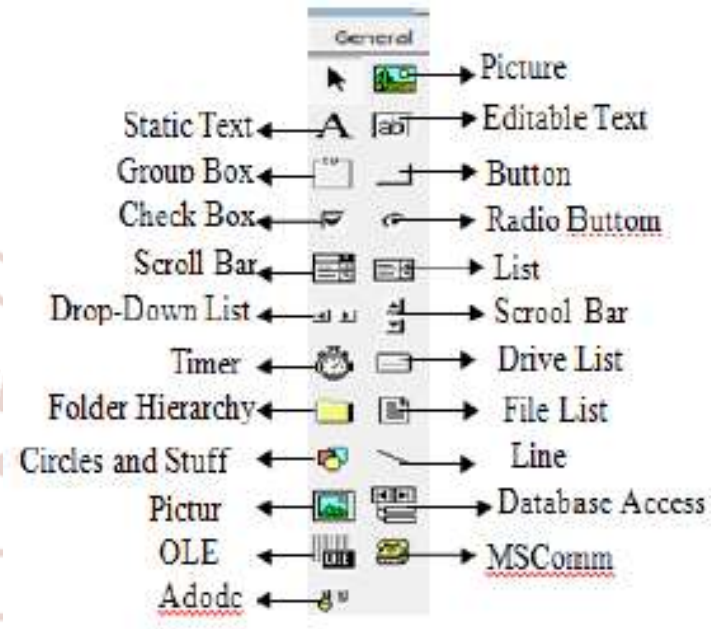

Fig 3: Type of Controls

This system starts with that controls for counter computer using label and text box from component toolbar. The factors of controls containing in table can be corrected in properties of component and by opening properties window from view menu.

\begin{tabular}{|c|c|c|c|c|}
\hline ND & ITEK NAME & FPIOE & QUANTITY & TOTAL \\
\hline Fetl" & Tex12 & Tek:3 & Ten.14 & $T e .45$ \\
\hline Fentlo & Tet? & Ters & $T e+19$ & Text 10 \\
\hline Text11 & Text12 & Tek:13 & Text14 & Text15 \\
\hline Text16 & Text7 & Tek:18 & Text19 & $\operatorname{Te}+20$ \\
\hline Tell21 & Tell2 & Tek23 & $T e \times 24$ & Ted 25 \\
\hline Tell2s & Ten:27 & Tek28 & $T e \times 29$ & Te. 400 \\
\hline Tel131 & $T \in{ }^{2} 3$ & Tek:33 & $T e+34$ & Te. 435 \\
\hline
\end{tabular}

Fig 4: Construction Table with GUI in Visual Basic 6.0

Fig. 5 shows usage of static text to select Com port and editable text. Click control to select and change properties.

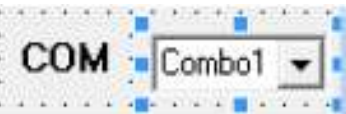

Fig 5: Control for Com Port 
International Journal of Trend in Scientific Research and Development (IJTSRD) ISSN: 2456-6470

Fig 6: is the properties window for combo1 command. To select Com port, combo1 command is built in the system.

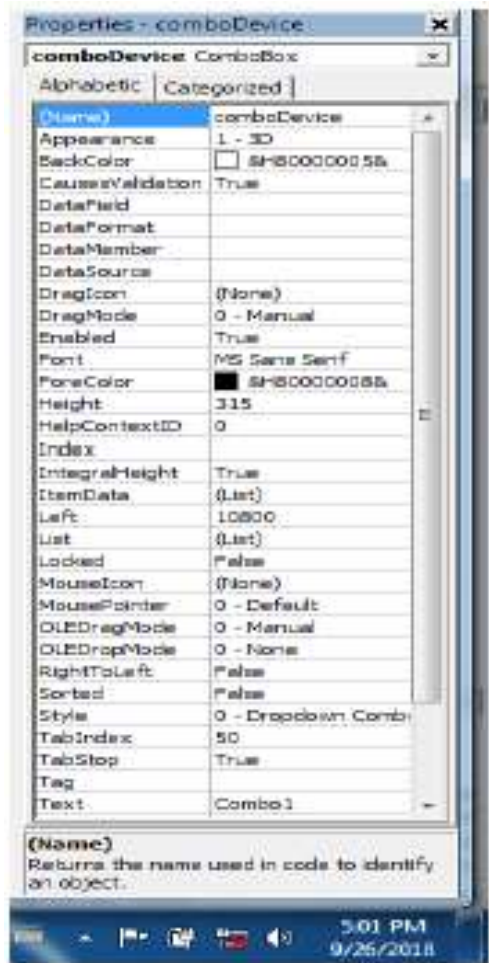

Fig 6: Properties Window for Com Port

The system will be take commands to build connect, disconnect, clear and exit command and reformed these components in properties window. Fig. 7 shows commands for Zigbee connection.

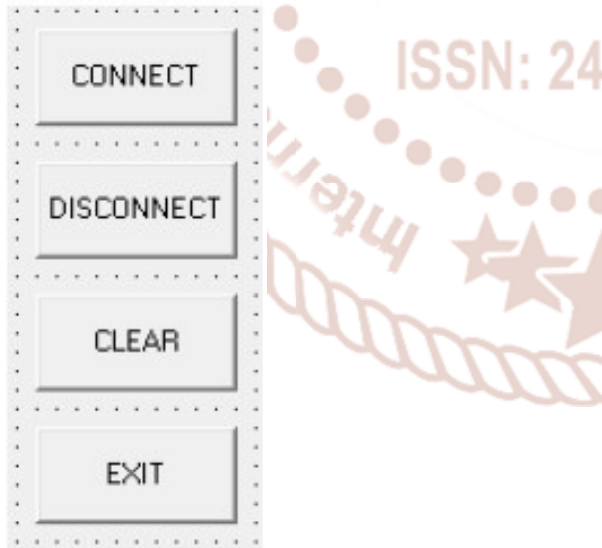

Fig 7: Commands for Zigbee Connection

Fig. 8 is Microsoft ADO Data Control (Adodc) control for record data. Adodc command is main command for database system and save command for recording daily customer bought items.

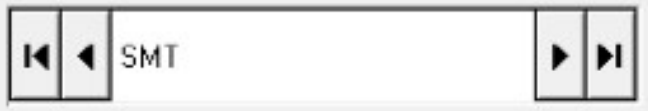

Fig 8: Adodc Command for Record Data
Fig. 9 shows the Visual Basic containing database commands.

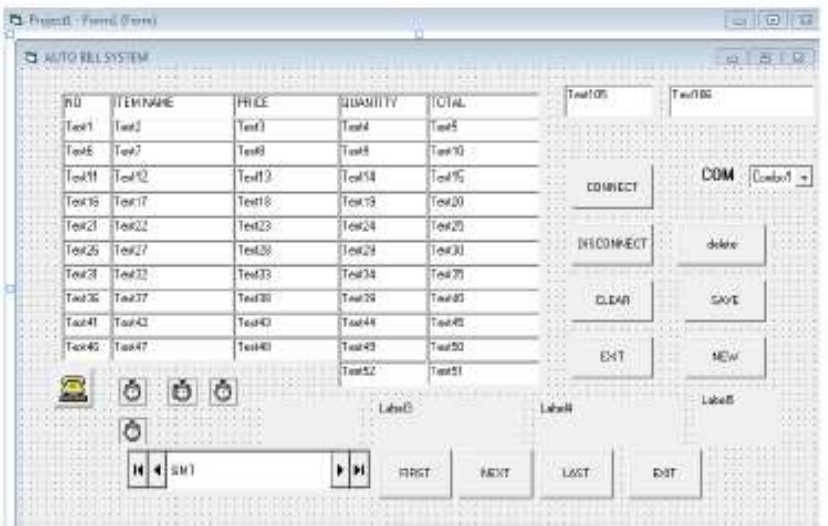

Fig 9: Visual Basic Containing Database Commands

The system creates the structure of a database in design view with table. When the table is created in the Access, data type column specifies the type of data that the field can contain. Fig. 10 shows the Microsoft Access database table in design view for the system.

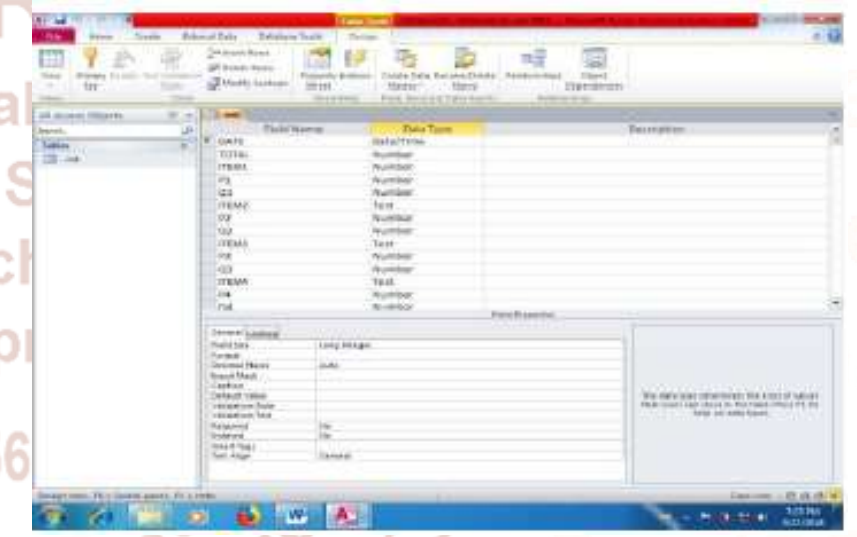

Fig 10: Design View for Microsoft Access Database Table

Fig. 11 shows circuit diagram for customer site. The complete system is implemented with the Arduino Uno connected with peripherals RFID reader, Zigbee and other module to meet the requisite.

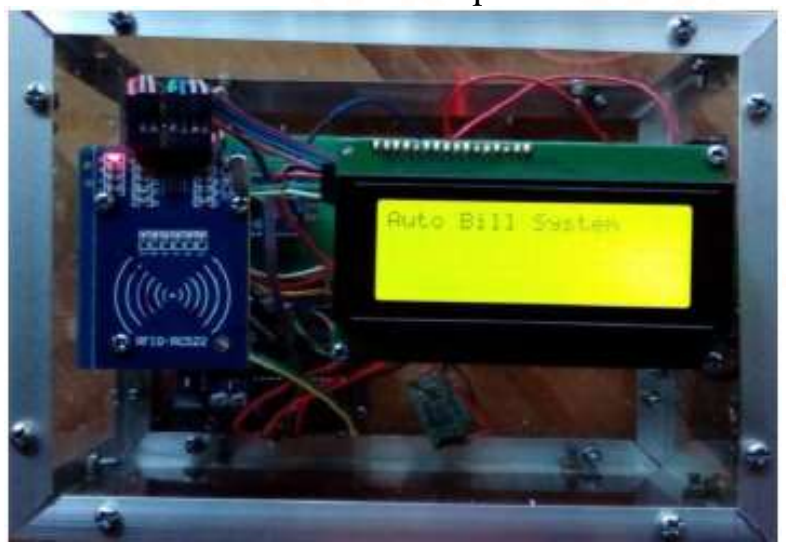

Fig 11: Circuit Design for Customer Site 


\section{EXPERIMENT AND RESULT}

Fig. 12 shows display products list on Automatic billing unit with Visual Basic software.

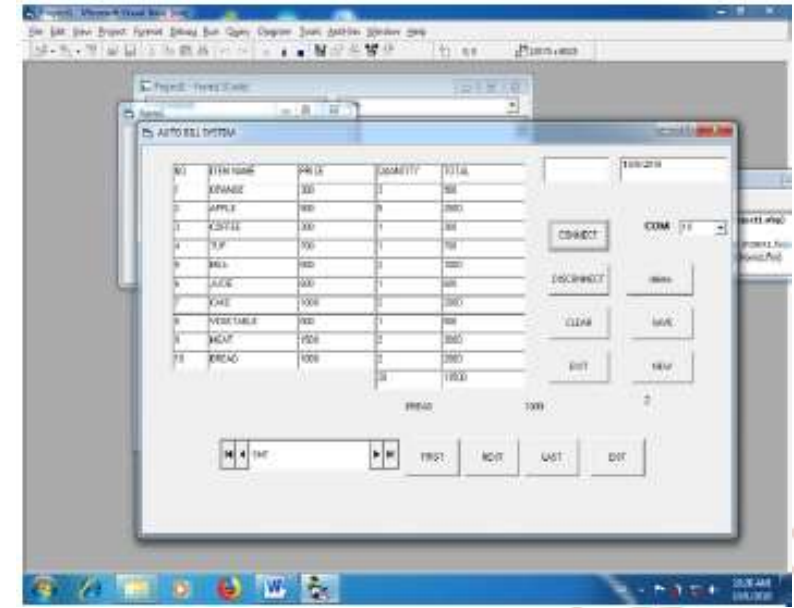

Fig 12: Display Products List on Automatic Billing Unit

Fig. 13 shows Microsoft Access 2007 database to know about details of purchasing products for shop owner.

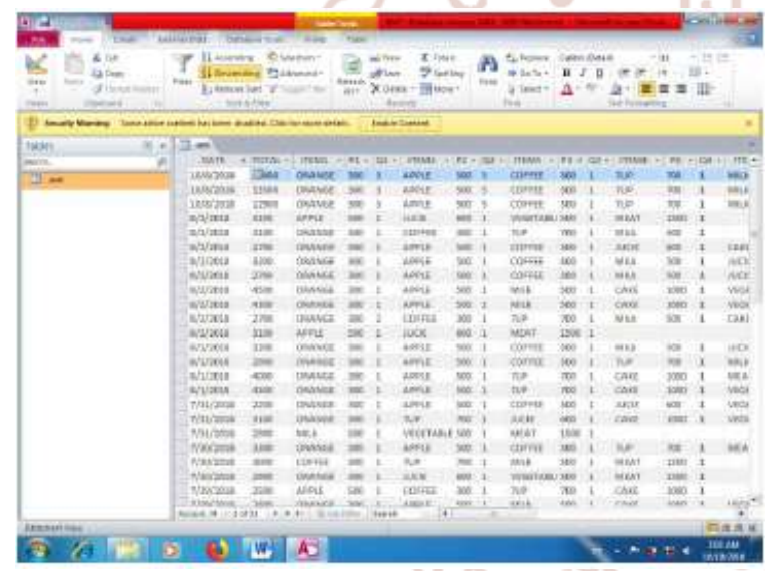

Fig 13: Database System for Shop Owner

\section{CONCLUSION}

The system for use in supermarkets will be advantage for shopping as it would make shopping easier. The idea of this paper is the customer needs not to stand in a queue to pay the bill. The system makes billing automatic arrive at the counter. The billing of this system is fast as the single product detail gets recorded from the customer site. Working on this product it was noted that RFID technology and Zigbee is a very vast applications in the near future. Also, RFID is better and faster than barcode reading because the later works on line of sight which is not the case for RFID technology is compact and reliable. Zigbee is the wireless network that connects the costumer to the retailer and is very secure with long range of operation. The RFID and Zigbee technology that are most commonly used would definitely find some use commercially.

\section{REFERENCES}

1. W. Durfee, University of Minnesota: Arduino Microcontroller Guide, October 2011, www.me.umn.edu/course/me2011/arduino

2. Aniket Wani, Krutike Thankur, Nikhil vaze, Meeta Vadhel, Prof. Rupali Advirkar: "RFID Based Intelligent Trolley System Using Zigbee," International Journal of Engineering And Computer Science ISSN: 2319-7242 Volume-4 ISSUE-3, March 2015, www.ijecs.in.

3. LuisFilipe, Technology Arduino Arduino: RFID Tag Reader/Manager, https://www.instructables.com/id/Arduino-RFIDTag-ReaderManager/ Mifare RC522 Card Read Antenna RFID Reader IC Card Proximity Module, 2015, http://www.ebay.com/itm/130892542303

4. Prof. S. H. Patil, Mayur Chaudhari, Amit Gore, Rajendra Kale and Prof. H. A. Hingoliwala: "A Survey on Technologies Used for Billing System in Supermarkets," International Journal of InnovativeResearch in Science, Engineering and Technology, Vol-4, ISSUE-10, October 2015.

5. Sandeep Kaundal: How to add,Update ,Delete and Clear records using Ms Access Database and Visual Basic 6.0 ADODC control -(Step by step full tutorial with explanation of each step)-An Advanced Visual Basic Database Application, September 28, 2015,

6. https://www.youtube.com/watch?v=tYS7uncH8D $\mathrm{s} \& \mathrm{t}=597 \mathrm{~s}$

7. Sreejeesh, Technology Arduino: Two wire interfacingof LCD with Arduino Nano : 5 steps, $2016 \mathrm{https}: / / \mathrm{www}$. instructables.com/id/Two-WireInterfacing-of-LCD-With-Arduino-Nano/

8. [17Aim] Aimee Kalnoskas: How do RFID tags and reader antennas work?, May 2, 2017, http://www.analogictips.com/rfid-tag-and-readerantenna.

9. Anonymous: ZIGBEE XBEE S2C-How to Configure as coordinator, Router/End Device, January 23, 2017, https://www.alselectro.wordpress.com.

10. RFID JOURNAL, 2002-2007, REFFERD 6.8.2007, http://www.net/vb6/vbtutor.html visual basic 6 tutorial. 